\title{
PEREIRA, Gustavo. Las voces de la igualdad. Bases para una teoría crítica de la justicia. Montevideo: Ed. Proteus, 2010. 288p.
}

Quais as vozes, isto é, as teorias de justiça mais capacitadas a fornecer uma boa fundamentação, um adequado critério de análise das situações de injustiça e uma eficiente força normativa, atendendo assim às demandas por justiça nas sociedades contemporâneas, tanto no nível institucionalizado, quanto no nível não institucionalizado da cultura, da moral pessoal e das relações interpessoais? Que meios são os mais adequados para promover os anseios por igualdade, oportunidade, liberdade, autonomia, participação e comprometimento próprios de nosso tempo? Que prioridades devem nortear os investimentos sociais e ações concretas na esfera política que promovam a justiça e a igualdade e, ao mesmo tempo, que consolidem a adesão ativa de todos - e de cada cidadão - à promoção de uma cultura cujo princípio ético fundamental, que se manifeste tanto nas instituições quanto na moral pessoal, seja o de uma sociedade fundada sobre a ideia - e os sentimentos relacionados - de "eticidade democrática"? No livro "As vozes da igualdade" ("Las voces de la igualdad. Bases para una teoría crítica de la justicia". Ed. Proteus, 2010. 288 páginas - Ainda sem tradução para o português), o Prof. Dr. Gustavo Pereira, da Universidad de la Republica, Uruguai, procura analisar estas questões investigando as principais teorias de justiça contemporâneas que pretendem respondê-las e apresenta sua proposta de um caminho para a fundamentação de uma teoria crítica de justiça renovada, mais abrangente, que ofereça meios mais adequados e eficazes para promover a justiça social e desenvolver as capacidades humanas necessárias para a construção de uma "eticidade democrática". Por fim, o autor apresenta uma investigação do que considera algumas das principais capacidades humanas e meios institucionais e não institucionais para construir uma eticidade democrática.

Um dos princípios fundamentais que sobressai nas vozes das atuais teorias de justiça é o que Gustavo Pereira chama de um "ideal normativo irredutível" - e poderíamos dizer, também, 'inegociável' - das sociedades contemporâneas: o "ideal igualitário", a autocompreensão e a expectativa

\begin{tabular}{|l|l|l|l|l|l|} 
Veritas & Porto Alegre & v. 56 & n. 3 & set./dez. 2011 & p. 191-196 \\
\hline
\end{tabular}


intersubjetiva que as pessoas têm como "seres a quem se deve um igual tratamento e a concomitante exigência de ser assim tratado" (p.14), abrangendo assim as dimensões éticas do dever-ser ideal e do ser efetivado e objetivo. Autocompreensão esta fortemente desenvolvida a partir da Modernidade, de nossa condição de pessoas como fins em si mesmos e nunca meios para outra coisa, valor sem preço, no que reside aquilo que Kant chamou de dignidade, valor incomparável e, portanto, supremo de cada pessoa.

Duas vozes alternantes, ora concorrentes, ora consoantes, ambas fundadas sobre uma ideia de igualitarismo, porém com critérios e vieses práticos distintos, porque de fato partem de princípios e fundamentações normativas distintos, que sobressaem no cenário contemporâneo da discussão sobre teoria da justiça e propostas ético-políticas, são expostas e analisadas no Capítulo I desta obra: de um lado, a teoria fundamentada sobre o 'princípio de redistribuição', defendida por Nancy Fraser. De outro, a 'teoria do reconhecimento', proposta por Axel Honneth.

$O$ autor, ao analisar ambos paradigmas e apresentar suas insuficiências e possíveis correções internas, e ainda caminhos para uma nova proposta que cubra as lacunas de ambos, mostra que, se analisarmos enfocando as características mais marcantes e salientando as peculiaridades e diferenças de cada modelo, podemos chegar a uma caracterização do que distingue mais claramente um modelo do outro. No entanto, há também aspectos que se interseccionam ou se sobrepõem, e mesmo tentativas de incorporar princípios e critérios da parte de um modelo sobre o outro. De todo modo, há que atentar para alguns fatores de risco na tentativa de corrigir as lacunas: a assimetria entre os conceitos de justiça e de reconhecimento, isto é, o risco de a justiça distributiva ser interpretada de certo modo como um mero agregado em uma teoria da justiça; o risco de que a proposta baseada no princípio de reconhecimento resulte em uma visão demasiado compreensiva que afete as liberdades individuais; o risco de interpretar a história simplificadamente como uma alternância periódica entre os dois modelos; o problema de fazer depender o princípio de uma determinada antropologia e, com isso, dificultar a justificação do caráter de obrigatoriedade das normas.

No que toca às distinções, no paradigma da distribuição, sustentado por Fraser, cuja linhagem é compartilhada pelas correntes de corte liberal, a ênfase da teoria da justiça assenta sua fundamentação, critérios e base de informação sobre aspectos de caráter sócio-econômicos, e o princípio de normatividade estabelece-se sobretudo na dimensão institucional jurídico-política.

$\mathrm{Na}$ teoria do reconhecimento, Honneth pretende introduzir uma mudança de paradigma, se bem que não rejeitando absolutamente 
o princípio da justiça distributiva. Para Honneth, o primeiro e mais forte princípio que sustenta a justiça em geral e, portanto, também a possibilidade da justiça distributiva, é o princípio do reconhecimento. Isto significa mudar radicalmente a fundamentação e o ponto de partida. O movimento de consolidação ética mais forte e eficiente não se dá da esfera institucional para o âmbito da moral pessoal e dimensões afetivas intersubjetivas. Ao contrário, a força de adesão à norma tem seu maior sustento no nível pessoal e intersubjetivo, nível dos afetos compartilhados e do reconhecimento mútuo. É esse reconhecimento partindo do nível afetivo o que dá força racional às normas e efetividade às ações institucionais, também na dimensão econômica e política da justiça distributiva. Esta dimensão relacional expressa a matriz hegeliana da teoria. O aspecto kantiano aparece no seu acento crítico, formal e no ponto de partida subjetivo e intersubjetivo, que culmina, segundo seus críticos, na fraca capacidade de objetivação e dificuldade de efetivação.

$\mathrm{Na}$ comparação destes dois modelos, aparecem suas virtudes, argumentos fortes e debilidades. No capítulo II, Gustavo Pereira propõe um caminho para identificar a melhor proposta de fundamentação da teoria crítica da justiça, isto é, que atenda à exigência posta pelos frankfurtianos de que uma tal teoria seja capaz de oferecer um diagnóstico crítico eficiente da realidade social (p. 86), para o que considera os dois modelos citados, enfatizando e incorporando suas virtudes, e pretendendo apresentar propostas para corrigir suas deficiências, tanto quanto isto seja possível. Em alguns aspectos, é preciso mesmo desenvolver maior fundamentação onde não há suficiente. No modelo da justiça distributiva, o aspecto normativo é mais fortemente enfatizado, se bem que carecendo um tanto em fundamentação filosófica. A capacidade de atender aos anseios e às dimensões mais pessoais, ao nível dos microcosmos do cotidiano e das particularidades, a capacidade de atentar para as diferenças mais sutis, ficam um tanto a desejar. No modelo da ética do reconhecimento, Honneth amplia a base empírica exigida por Habermas; contempla dimensões mais profundas do ser humano, o cotidiano dos afetos e das relações intersubjetivas, a dimensão da moral pessoal, dos sentimentos e das emoções; porém, carecendo de uma antropologia política, a dimensão normativa e a aplicabilidade prática da justiça apresentam-se com consideráveis debilidades (p. 92-93).

Tanto Honneth quanto Fraser incorporam dimensões de justiça e de reconhecimento para garantir direitos iguais, igualdade de cidadania, distribuição de bens e recursos, e o reconhecimento diferencial de qualidades e capacidades. Gustavo Pereira apresenta alguns pontos marcantes a fortalecer. Por um lado, há que se promover um ponto de vista que transcenda e encarne mais na realidade social, formada por 
indivíduos, valores pessoais e costumes, que pressione mais além da ordem social instituída vigente. O critério da paridade participativa proposto por Fraser tem um alcance mais objetivo e material, mas descurando de certo modo a dimensão intersubjetiva. Por outro lado, no aspecto da teoria crítica da justiça tal como proposta por Honneth, em que um critério fundamental é o conceito de autorrealização - a um só tempo princípio, thelos e critério de averiguação - há que se ir mais a fundo na investigação das possibilidades de tratamento igualitário, dos conceitos de 'vida boa' e de autorrealização, para assegurar a viabilidade de se constituir a partir destes conceitos uma base de informação objetiva e a aplicabilidade da norma. A capacidade de transcendência do estado de coisas socialmente instituído e a amplitude crítica na teoria de Honneth é mais potente, mas a normatividade e a institucionalização em Fraser são mais objetivas, aplicáveis e fortes.

A chave para interpretar e corrigir as distorções das teorias está no conhecimento da base de informação adotada em cada modelo. A base de informação de Fraser considera, sobretudo, os aspectos econômicos e institucionais. A base de informação de Honneth pretende atingir o conhecimento de esferas de acentuado caráter particular e diferenciadas, como as esferas dos valores pessoais e de grupos, as necessidades de reconhecimento afetivo e as dimensões emocionais da vida social, o que por si só exige uma investigação exaustiva, o mais ampla possível, e em permanente crítica e reformulação dos quadros descritivos e interpretativos dos diversos fenômenos, conflitos e ações sociais.

O professor Gustavo Pereira sintetiza os aspectos fundamentais que deve ter uma teoria de justiça ao mesmo tempo crítica e aplicável:

- como princípios: os ideais igualitários, isto é, baseados na ideia de igual dignidade; a consideração da dimensão intersubjetiva expressa no reconhecimento recíproco dos valores, capacidades e vulnerabilidades pessoais, e também das situações de vulnerabilidades estruturais - o que leva aos princípios derivados de justiça distributiva e justiça compensatória; contar com um substrato cultural de valores, crenças e fins, se bem que diferenciados, mas concordes tendo em vista o princípio prático fundamental da eticidade democrática; uma reflexão permanentemente aberta, com base numa ética do discurso ao molde habermasiano, sobre as ideias de autorrealização, vida boa e bem; uma fundamentação filosófica de corte pragmático-transcendental ao modo de Apel, onde a possibilidade e efetividade permanente do discurso é o motor e o thelos, o princípio atrator da razão prática, sustentado colateralmente por uma fundamentação deontológica que garanta a possibilidade de normatividade e institucionalização; 
- para a análise e crítica do fenômeno social: uma base de informação ampla, sobre os aspectos econômico-distributivos, políticos, e também sobre as capacidades, qualidades e valores pessoais a serem cultivados cujo sentido teleológico é a emancipação, a participação nas deliberações, o sentimento interno e ao mesmo tempo a prática de ser cidadão, sentimento de pertença e de responsabilidade, enfim, a autorrealização e o cultivo de uma ideia de justiça fundada sobre o princípio de eticidade democrática. A eticidade democrática é, assim, o conceito que sintetiza o valor maior a ser promovido, o conceito fundamental de bem a ser buscado com base nesta teoria da justiça.

Por fim, no capítulo III, Gustavo Pereira apresenta ainda alguns elementos de sua proposta para a construção efetiva de uma eticidade democrática, com uma investigação das principais capacidades humanas, recursos e meios necessários, a seu ver, para tal fim. Estes meios e capacidades apresentados na proposta do autor estão em correlação, mas não exaustivamente, com a tripla estrutura do conceito de "mundo da vida" (p. 199), de Habermas, o "horizonte em que os agentes comunicativos se movem já desde sempre" (p. 182), apresentada no capítulo anterior. Esta estrutura é expressa em três níveis: cultura, sociedade e personalidade. Segundo Cohen, estes podem ser bem expressos em dois níveis: o nível institucional, das ações em sociedade; e o nível cultural-linguístico, que envolve o mundo da cultura, o mundo pessoal e interpessoal, e a relação entre ambos. As propostas ético-políticas, portanto, devem enfocar estas três dimensões: ser propostas que possibilitem a institucionalização normativa; e que se expressem no espaço não institucional da cultura e dos valores pessoais e das relações intersubjetivas particulares.

Assim, algumas das capacidades humanas necessárias são: emancipação política e econômica; autonomia moral, participação na razão pratica pública e responsabilidade; emoções e sentimentos cívicos, como estima, compaixão, gratidão, piedade; perdão, pertença, empatia, abertura à alteridade e à diferença; virtudes cívicas, como sentido crítico, solidariedade, disposição de abertura ao diálogo, e capacidade de "autocoação", isto é, de comprometer-se desde sua própria racionalidade prática à participação ativa plena.

Gustavo Pereira propõe alguns meios pra atingir o fim proposto, que aqui resenhamos apresentando segundo as seguintes dimensões:

- na dimensão material, própria do enfoque da justiça distributiva, trata-se de garantir o acesso igualitário aos bens fundamentais: alimentação, educação, habitação, estabilidade financeira, oportunidade de trabalho, possibilidades de autorrealização; 
- na dimensão institucional: preservação fundamental de um contexto relacional aberto de discurso e reflexão; capacidade política de detecção das situações de vulnerabilidade social e de ações distributivas e compensatórias capazes de reduzir os diferentes graus de vulnerabilidade e dependência; o papel do direito como promotor do cultivo da eticidade democrática;

- na dimensão teórica: revisão permanente da própria teoria crítica da justiça e das bases de informação consideradas;

- na dimensão cultural: cultivo das capacidades humanas citadas; promoção da abertura à alteridade e às diferenças, e da reflexão sobre conceitos de justiça, bem e vida boa, através das narrações, literatura, etc.; aprendizagem das capacidades fundamentais; aprendizado emocional; e ainda a necessária preservação de um devido espaço de dissenso.

O leitor encontrará na obra uma exposição mais detalhada e aprofundada sobre estas capacidades e meios para a construção de uma eticidade democrática, aqui resenhados. Como observa o próprio autor, porém, não pretende com isso uma expressão exaustiva e definitiva de capacidades e meios, uma vez que um dos princípios teóricos é resguardar uma provisoriedade e uma incompletude inerentes à teoria crítica de justiça (p. 150), que possibilita sua permanente revisão e complementação, assim como dos critérios e, consequentemente dos meios propostos em consonância. O que pretende com a obra, sobretudo, é apresentar uma proposta de possíveis caminhos a seguir para atingir efetivamente estes fins. 